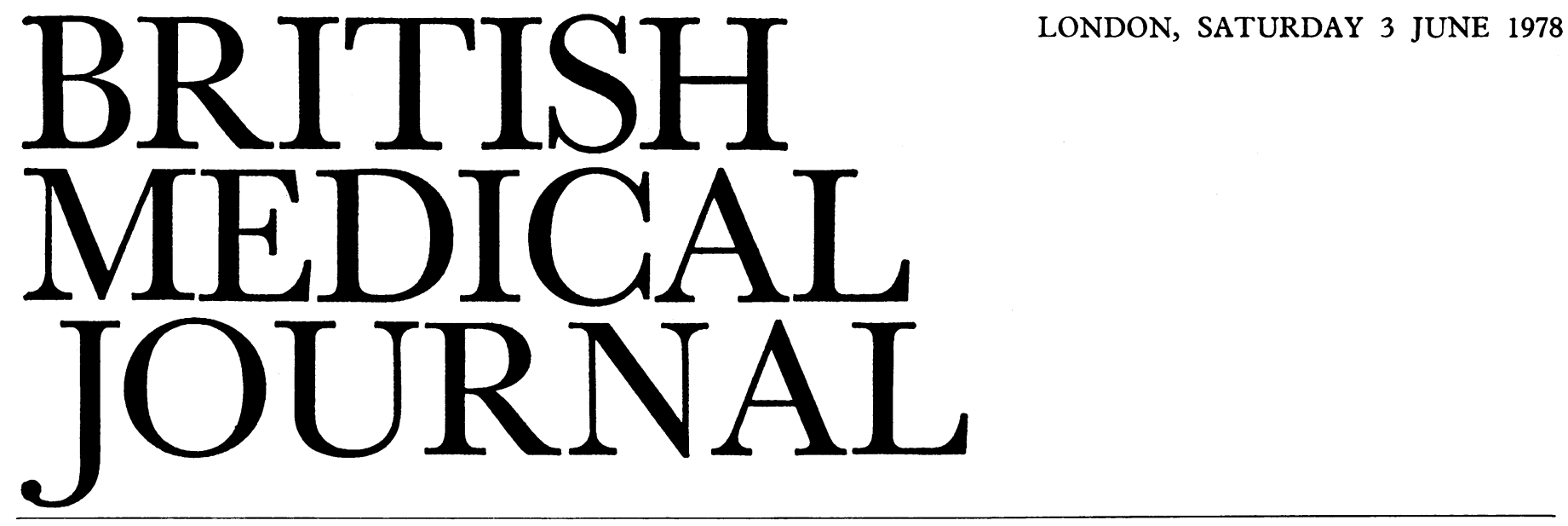

\title{
Cimetidine for ever (and ever and ever ....)?
}

The histamine $\mathrm{H}-2$ antagonist cimetidine was released for general use in Britain 18 months ago. By then a mass of published work had shown it and its toxic predecessor metiamide to be such potent suppressors of gastric acid secretion that their effects on upper gastrointestinal function and disease were likely to be revolutionary.

Today we have no doubt about the value of cimetidine for healing acute duodenal ulcers and for relieving symptoms, compared with a placebo. ${ }^{12}$ On the other hand, compared with "intensive" antacid treatment, there is little difference in the effects on diminished gastric acid $^{3}$ and therapeutic benefit. ${ }^{4}$ Nevertheless, taking $210 \mathrm{ml}$ of daily antacid is less convenient and more expensive and will provoke diarrhoea. ${ }^{34}$ For the acute ulcer cimetidine is clearly the better choice. What remains to be seen is how long its effects will last and how the clinician should best use the drug in managing patients with chronic ulcers.

Early experience with metiamide ${ }^{5}$ suggested that prolonged treatment at full dosage would keep symptoms at bay. Treatment with cimetidine twice daily for a year prevents endoscopic recurrence, ${ }^{6}$ and, since the drug is most potent in suppressing fasting acid secretion, a single nocturnal dose of $800 \mathrm{mg}^{7}$ or even perhaps $400 \mathrm{mg}^{89}$ should be equally effective. The report of a double-blind trial in the $B M \mathcal{F}$ in April from GudmandHøyer and his colleagues ${ }^{10}$ showed that symptomatic benefits were maintained for a year, but that once treatment was stopped relapses were frequent. Indeed, the consensus at a recent meeting in Edinburgh was that from the moment treatment with cimetidine ceases ulcers start to recur, usually with a characteristic painful exacerbation, but sometimes painlessly (discovered by endoscopy performed as part of surveillance). After six months $70 \%$ to $80 \%$ have recurred, most of them in the first few weeks..Moreover, continuing cimetidine, even at a dose of $400 \mathrm{mg}$ twice daily, does not completely prevent relapse. About one-fifth of the patients in Nottingham ${ }^{11}$ and Dundee $^{12}$ on this maintenance dose had ulcer recurrences within six months, though a report from Adelaide ${ }^{13}$ produced the more favourable figure of $10 \%$ in a year. Wormsley ${ }^{12}$ emphasised that about half the recurrences in his series were painless, presenting a hazard if these "treated" patients have the same risk of haemorrhage or perforation as if they were untreated. (There are two published reports of such perforations. ${ }^{14}$ 15)

It looks, therefore, as though six or twelve months' maintenance treatment with cimetidine, $400-800 \mathrm{mg}$ daily, does not alter the subsequent course of a patient's duodenal ulcer disease; once he stops the drug, in effect he "starts where he left off." Note that he is no worse, however. There is no evidence of "rebound," and, although basal concentrations of serum gastrin remain high for at least two weeks after stopping cimetidine, the gastrin responses to meals and gastric secretions of acid show no alteration. ${ }^{16}$

Is the answer, then, long-term treatment? Such a regimen must be assessed against a background of unanswered questions. Our knowledge of the aetiology, incidence, and natural history of chronic duodenal ulcer is still fragmentary, as is our understanding of the relation between ulceration, symptoms, and the uncommon but life-threatening complications of bleeding and perforation; moreover, the course of the disease in the individual patient is unpredictable. How effective even more prolonged treatment is likely to be can be answered only by further trials. The safety of such treatment is another matter. As new drugs go, cimetidine has a very good record. Gynaecomastia $^{17}$ and raised serum concentrations of creatinine $^{18}$ and prolactin ${ }^{19}$ have been reported, but these effects seem of little clinical importance. Studies in the rat with metiamide suggested the possibility of eventual parietal cell hypertrophy, ${ }^{20}$ but may not reflect the effect of cimetidine in man. More disturbing, perhaps because it is difficult to predict the possible consequences, is the finding of increased delayedhypersensitivity responses in man after six weeks' treatment. ${ }^{21}$

In our present state of knowledge prolonged treatment is justified in the management of gastrinoma, where some risk is acceptable. In chronic duodenal ulcer, indefinitely prolc nged treatment could be justified only if its safety had been proved. Not only has this not been done with cimetidine, the effect of such treatment on the disease itself has yet to be tested. Controlled trials with careful monitoring should (and doubtless will) continue, but treatment beyond a year cannot be justified at present in ordinary practice. If, however, the only alternative is frequent, disabling pain in a patient unsuitable for surgery then the balance may be tipped towards everlasting treatment. Where relapse is infrequent or mild, conventional treatment backed by occasional short courses of cimetidine seems bestwith surgery for the fit patient who suffers frequent and troublesome relapse.

Such a policy is easier to recommend than to follow: the practitioner who has gained a year of respite for his patient will be sorely tempted to continue, but he should refrain. The data sheet for the drug is correctly cautious about long-term prescription-but does anybody read data sheets?

\footnotetext{
${ }^{1}$ Bodemar, G, and Walan, A, Lancet, 1976, 1, 161.

${ }^{2}$ Gray, G R, et al, Lancet, 1977, 1, 4.

${ }^{3}$ Deering, T, and Malagelada, J R, Gastroenterology, 1977, 73, 11.
} 
4 Ippoliti, A F, et al, Gastroenterology, 1978, 74, 393.

5 Saunders, J H B, and Wormsley, K E, Lancet, 1977, 1, 765.

6 Bodemar, G, and Walan, A, Lancet, 1978, 1, 403.

${ }^{7}$ Blackwood, W S, et al, Gut, 1977, 18, A420.

${ }^{8}$ Longstreth, G F, et al, New England fournal of Medicine, 1976, 294, 801

${ }^{9}$ Gray, G R, et al, Gastroenterology, 1978, 74, 3987.

10 Gudmand-Høyer, E, et al, British Medical fournal, 1978, 1, 1095.

11 Langman, J M S, Symposium on Management of Peptic Ulceration, Royal College of Surgeons of Edinburgh, April 1978

12 Wormsley, K G, Symposium on Management of Peptic Ulceration, Royal College of Surgeons of Edinburgh, April 1978.

${ }^{13}$ Hetzel, D, D, Symposium on Management of Peptic Ulceration, Royal College of Surgeons of Edinburgh, April 1978.

14 Wallace, W A, Orr, C M E, and Bearn, A R, British Medical fournal, 1977, 2, 865 .

15 Hoste, P, et al, Lancet, 1978, 2, 666.

16 Forrest, J A H, Symposium on Management of Peptic Ulceration, Royal College of Surgeons of Edinburgh, April 1978.

17 Hall, W, New England fournal of Medicine, 1976, 295, 841.

18 Blackwood, W S, et al, Lancet, 1976, 2, 174.

19 Delle Fave, G F, et al, Lancet, 1977, 1, 1319.

${ }^{20}$ Witzel, L, et al, Gastroenterology, 1977, 73, 797.

${ }^{21}$ Avella, J, et al, Lancet, 1978, 1, 624

\section{Hazards of epilepsy}

Bland words of reassurance do little to relieve the anxiety of parents fearful that a fit during sleep may kill their epileptic child. Familiarity with recurrent fits may eventually give them confidence-as they believe that the next fit will be as stereotyped and innocuous as the last. Some parents, however, do not get over the shock of witnessing the first convulsion, convinced that their child-apnoeic, stiff, and cyanosed-was dying; and it may lead to such a degree of watchful overprotection that epilepsy comes to dominate the life of the family.

A divided nightly vigil shared by parents is perhaps the extreme variant of this fear, but some worry about suffocation in a nocturnal fit is common, especially in parents of the very young. This may lead them to install a baby alarm, or share the same bed (usually with the willing collusion of the child, whose demanding behaviour may reflect the exceptional indulgence which parental anxiety breeds). This anxiety-and the restrictions of freedom which it generates-must be seen as counterproductive. Though difficult to measure, psychosocial factors are widely believed to influence the frequency and character of fits in children (as in adults), and in many children there appears to be a vicious circle of parental anxiety and poor control of fits. Yet much of our medical advice serves to consolidate rather than relieve these difficulties-for example, the recommendation of anticonvulsant medication is sometimes bolstered by the threat of brain damage through noncompliance, and swimming and cycling may be forbidden because of the harm that might accompany a fit occurring in potentially hazardous circumstances.

How valid are these well-intentioned but frustrating restrictions? Most studies of comparative risk rates for drowning, suffocation in bed, or trauma in patients with epilepsy have been based on patients in long-stay hospitals or mental subnormality units and have not included corrections for differing policies of management. ${ }^{1-4}$ Simply because so many epileptics are dissuaded from swimming and driving, statistics of drowning and of road traffic accidents cannot identify the size of the potential hazard. Nevertheless, what evidence we have suggests that misadventure is relatively rare.

For example, the Brisbane Drowning Study ${ }^{3}$ showed that, though the risk of drowning was four times greater in epileptic children who swam than in normal children, the absolute risk remained low. ${ }^{6}$ Among the 107 deaths at all ages in the 10-year review of patients at the Norwegian State Hospital for Epilepsy and in the neurological unit of the University of Oslo three were due to accident and 11 to drowning. ${ }^{2}$ Other $w$ population studies have shown few or no excess deaths due to epilepsy except in those patients (mostly children) who are mentally or physically handicapped, ${ }^{7}$ who tend to have more $c$ severe epilepsy anyway. At a children's psychiatric hospital ${ }^{1} \ddot{\Rightarrow}$ there was no difference in the rate of injury among epileptic $\stackrel{\text { ? }}{+}$ and non-epileptic children "engaged in a full athletic programme" $\left(2.9 \%\right.$ and $2.8 \%$ respectively). From the infrequency $\frac{\bar{\sigma}}{\bar{\omega}}$ of reports of death during sleep ${ }^{8}$ apparently due to suffocation $\vec{\nabla}$ during a fit the hazard may be presumed rare-especially in comparison with the frequency of nocturnal fits in children. क

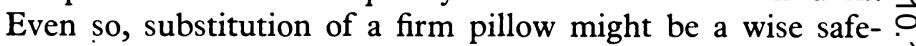
guard.

Generally, therefore, the picture is reassuring. Most of the traditional restrictions on epileptics, though well justified in $\frac{5}{3}$ theory, can be waived in practice, though not entirely abandoned. The enlightened medical director of the largest residential school in Britain for children with epilepsy has $N$ encouraged building a swimming pool at his school, arguing $\vec{A}$ that the need to be able to swim is even greater for his pupils than for others. Swimming under supervision should be possible for all but the most poorly controlled patients. $\omega$ Nevertheless, for bathing a shower is preferable to the bath- $\complement$ tub for those children who demand privacy.

Cycling, too, is permissible for children with well-controlled $\vec{\bullet}$ fits or with "situation-dependent" or nocturnal attacks, if they have access to uncluttered highways. Sadly, for many (including normal) children this is an almost unattainable ideal in large conurbations. What constitutes good control of fits is an arbitrary judgment. Important factors in the decision whether or not to discourage cycling include not only the frequency $\stackrel{\mathbb{Q}}{\Omega}$ of fits but also the amount of warning. School teachers often $\overrightarrow{\vec{A}}$ need guidance as much as parents. Their fearful prejudices $\exists$ may be unnecessarily restrictive, and they need an enlightened view of the management of epilepsy with a willingness to include rather than exclude sufferers in school activities.

\section{${ }^{1}$ Aisenson, M R, Pediatrics, 1948, 2, 85. \\ 2 Krohn, W, Epilepsia, 1963, 4, 315. 1960. $1954,156,1526$ 2, 942 . \\ 6 Pearn, J S, British Medical fournal, 1977, 1, 1510 Worcester-Drought, C, Lancet, 1970, 2, 876 \\ Epidemic myalgic encephalomyelitis}

${ }^{3}$ Lennox, W G, Epilepsy and Related Disorders, vol 2. London, Churchill,

${ }^{4}$ Schwade, E D, and Otto, O, fournal of the American Medical Association,

'Pearn, J H, Nixon, J, and Wilkey, I, Medical Yournal of Australia, 1976,

${ }^{7}$ Livingston, S, Living with Epileptic Seizures. Springfield, Thomas, 1963.

Outbreaks of the paralytic disease known as epidemic myalgic encephalomyelitis have puzzled doctors all over the world in the past 30 years. One of the best known of these epidemics was that at the Rnyal Free Hospital in London in 1955, which affected more than 300 people. ${ }^{1}$ Most outbreaks tend to occur in the summer, young adults are predominantly affected, and the incidence is higher in women. The evidence suggests that infection is spread by personal contact, and young hospital personnel seem particularly at risk. The features common to 